\title{
El cabildo de la catedral de Pamplona: Composición social, carreras canonicales y conflictividad en el siglo XIII (1194-1266) ${ }^{*}$
}

\section{The Cathedral Chapter of Pamplona: Social Composition, Canonical Careers, and Conflictiveness in the Thirteenth Century (1194-1266)}

Cristina M ${ }^{\mathrm{a}}$ GARCÍA GARCÍA

Contratada predoctoral por la Universidad de Zaragoza. Área de Historia Medieval, Departamento de Historia Medieval, Ciencias y Técnicas Historiográficas y Estudios Árabes e Islámicos, Facultad de Filosofía y Letras, Universidad de Zaragoza, Calle Pedro Cerbuna 12, 50009, Zaragoza, España.

C. e.: cmgarcia@unizar.es

ORCID: https://orcid.org/0000-0003-2083-9519

Recibido: 05/10/2017. Aceptado: 19/12/2017.

Cómo citar: García García, Cristina M., «El cabildo de la catedral de Pamplona: Composición social, carreras canonicales y conflictividad en el siglo XIII (1194-1266)», Edad Media. Revista de Historia, 2018, no 19, pp. 241-268.

DOI: https://doi.org/10.24197/em.19.2018.241-268

Resumen: Este trabajo recoge los resultados de un estudio prosopográfico de los canónigos de la catedral de Pamplona en la primera mitad del siglo XIII, que ha permitido determinar el origen geográfico y social de los religiosos, conectar la comunidad con el entramado social de la ciudad y del reino y revisar los conflictos que se produjeron durante este periodo en el seno de la institución y, en particular, entre el cabildo y los obispos. Este análisis permite, además, verificar las características de la promoción social establecida a través del capítulo. Como conclusión, se puede afirmar que esta fase de crecimiento de la Iglesia pamplonesa estuvo acompañada por dificultades internas que muestran cómo estos años constituyen un umbral decisivo en la evolución del cabildo catedralicio.

Palabras clave: Cabildos catedralicios; Élites eclesiásticas; Jerarquización eclesiástica; Conflictividad eclesiástica; Pamplona; Reino de Navarra; Siglo XIII.

Abstract: This research article compiles the results of a prosopographical study of the canons of the Cathedral of Pamplona during the first half of the thirteenth century, that has enabled us to

Este trabajo se ha llevado a cabo gracias a una subvención FPI de 2016 concedida por el MINECO y cofinanciada por el Fondo Social Europeo. Asimismo, se integra en el proyecto I+D+i del MINECO: Las transformaciones del Estado: estructuras políticas, agentes sociales y discursos de legitimación en el reino de Aragón (siglos XIV-XV). Una perspectiva comparada (ref. HAR2015-68209-P), cuyo investigador principal es Carlos Laliena Corbera, y en las líneas del Grupo de Investigación Consolidado CEMA financiado por el Gobierno de Aragón (cema.unizar.es). Agradezco a Carlos Laliena Corbera y María Narbona Cárceles su ayuda en esta investigación, sin que ello los haga responsables de las afirmaciones que aquí se realizan. 
determine the geographical and social origin of these clerics, to connect the community with the social framework of the city and the kingdom, and to revise the conflicts that broke out in the period within the institution, and in particular, between the canons and the bishops. Besides, the analysis has revealed the characteristics of the social promotion afforded by the charter. In conclusion, we can assert that this growing stage of the Church of Pamplona coexists with serious difficulties that prove how these years turned out to be a decisive period in the chapter's development.

Keywords: Cathedral Chapters; Ecclesiastical Elites; Ecclesiastical Hierarchy; Ecclesiastical Conflictiveness; Pamplona; Reign of Navarre; Thirteenth Century.

Sumario: 0. Introducción. 1. El origen de los canónigos de la catedral de Pamplona. 2. Jerarquía y organización interna: carreras canonicales y acceso a las principales dignidades. 3. Enfrentamientos y ruptura de la jerarquía eclesiástica: promociones frustradas y disputas con el episcopado. 4. Consideraciones finales. 5. Bibliografía.

Summary: 0. Introduction. 1. The origin of the canons of the Cathedral Chapter of Pamplona. 2. Hierarchy and internal organisation: Canonical careers and promotion to major dignities. 3. Confrontation and breach within the church hierarchy: Frustrated promotions and quarrels with the bishopric. 4. Final remarks. 5. Bibliography.

\section{INTRODUCCIÓN}

En las últimas décadas, la preocupación de la historiografía europea e hispánica por las instituciones religiosas y los cabildos catedralicios medievales ha crecido de manera considerable, lo que ha permitido concretar los mecanismos a través de los cuales los canónigos desarrollaron formas de dominación específicas, resaltar el papel del clero capitular como instancia de poder dentro de la organización jerárquica de la Iglesia y considerarlo parte de la élite social en múltiples diócesis medievales.

Esta trayectoria científica ha favorecido la consolidación en nuestro país de una temática que comenzó a cristalizar en la década de 1960 y cuya evolución a lo largo de medio siglo condujo desde planteamientos puramente institucionales, sostenidos por eruditos historiadores eclesiásticos, hacia el análisis de los patrimonios capitulares y las formas de organización económica, para adoptar en fechas más recientes nuevos enfoques de corte político y sociocultural ${ }^{1}$. Los

\footnotetext{
** Siglas y abreviaturas utilizadas: CDCP: Goñi Gaztambide, José, Colección diplomática de la catedral de Pamplona. 829-1243, Pamplona, Gobierno de Navarra, 1997; CCP: Id., Catálogo del Archivo Catedral de Pamplona (829-1500), Pamplona, Diputación Foral de Navarra, 1965; ACP: Archivo de la catedral de Pamplona; GPN: García Larragueta, Santos, El gran priorado de Navarra de la Orden de San Juan de Jerusalén. Siglos XII-XIII, Pamplona, Diputación Foral de Navarra, 1957; CDR: Ostolaza Elizondo, María Isabel, Colección diplomática de Santa María de Roncesvalles (1127-1300), Pamplona, Diputación Foral de Navarra, 1978; DAMP: Ciérbide Martinena, Ricardo; Ramos Remedios, Emiliana, Documentación medieval del Archivo Municipal de Pamplona (1129-1356), San Sebastián, Sociedad de Estudios Vascos, 1998; CDO: Munita Loinaz, José Antonio, «Regesta documental del monasterio de la Oliva (1132-1526)», Príncipe de Viana, 1995, 56, 205, pp. 343-484;
} 
estudios sobre la corporación de canónigos de Pamplona tuvieron hasta hace algo más de dos décadas a José Goñi Gaztambide como principal y casi único punto de referencia con su Historia de los obispos de Pamplona ${ }^{2}$; una obra que, si bien responde a un modelo centrado en la recuperación de datos sobre los obispos desde presupuestos estrictamente biográficos, arroja interesante información para entrever las relaciones entre episcopado y cabildo o la capacidad de los canónigos para manifestar su presencia en el escenario sociopolítico de la iglesia de Pamplona. La eficacia de este relato de corte convencional y el declive del interés por la historia eclesiástica preservaron un lugar de privilegio a esta síntesis del episcopado pamplonés hasta 1990, cuando la apertura de los archivos eclesiásticos dio paso a la publicación de nuevos trabajos que ampliaron considerablemente el marco conceptual de la obra de este excepcional archivero. El interés de algunos historiadores navarros por el estudio del cabildo pamplonés se ha dirigido en los últimos años hacia cuestiones como la proyección de los religiosos fuera de su propio espacio institucional o su comportamiento sociocultural ${ }^{3}$, lo que ha permitido empezar a comprender la significación que alcanzaron los canónigos en el marco de la sociedad pamplonesa y navarra de este tiempo. Sin embargo, la escasa atención prestada al alcance político de estos religiosos hace necesario abrir nuevas líneas de investigación que, a imagen de los estudios portugueses o

CAGC: Castro, José Ramón; Idoate, Florencio, Catálogo del Archivo General de Navarra. Catálogo de la sección de Comptos. Documentos. Tomo I (842-1331), Pamplona, Aramburu, 1952.

${ }^{1}$ Esta evolución se refleja en los balances historiográficos publicados hasta el momento. Citaremos los más recientes: Lop Otín, María José, «Las catedrales y los cabildos catedralicios en la Corona de Castilla durante la Edad Media. Un balance historiográfico», En la España medieval, 2003, 26, pp. 371404; Munsuri Rosado, Nieves, «Clero e Iglesia en la Baja Edad Media hispánica: estado de la cuestión», e-Humanista: Journal of Iberian Studies, 2008, 10, pp. 133-169; Vigil Montes, Néstor, «Últimas aportaciones a la historia de los cabildos catedralicios en Castilla y Portugal durante la Edad Media (2000-2010)», Studium Ovetense, 2010, 28, pp. 103-133.

2 Véase Goñi Gaztambide, José, Historia de los obispos de Pamplona. Tomo I. Siglos IV-XIII, Pamplona, Gobierno de Navarra, 1979. Otros trabajos de este autor relacionados con el tema que nos ocupa son: Id., «La formación intelectual de los navarros en la Edad Media (siglos XII-XV)», Estudios de la Edad Media de la Corona de Aragón, 1975, 1975, pp. 143-303; Id., «Episcopado y cabildo», en Jusué Simonena, Carmen (dir.), La catedral de Pamplona. Tomo I, Pamplona, Caja de Ahorros de Navarra-Gobierno de Navarra, 1994, pp. 33-69 o Id., Los priores de la catedral de Pamplona, Pamplona, Mintzoa, 2000.

${ }^{3}$ Algunos de los más interesantes son el análisis prosopográfico llevado a cabo por Francisco Javier Jiménez o los estudios más recientes de Ángeles García de la Borbolla. Véase Jiménez Gutiérrez, Francisco Javier, «El cabildo pamplonés en el siglo XIV. Un análisis prosopográfico», Príncipe de Viana, 1992, 53, 196, pp. 391-408; García de la Borbolla, Ángeles, «La identidad de los canónigos de la catedral de Pamplona en el siglo XIV: figuras destacadas y dignidades», Príncipe de Viana, 2016, 77, 265, pp. 715-731; Id., «El cabildo de la catedral de Pamplona y la Navarrería en la segunda mitad del siglo XIV: la creación de un condominio», Edad Media: revista de historia, 2016, 17, pp. 255-273 e Id., «Encuentros y desencuentros en el seno del cabildo de la catedral de Pamplona (siglo XIV)», Historia. Instituciones. Documentos, 2016, 43, pp. 171-182. 
franceses ${ }^{4}$, permitan comprender su papel en la catedral, en la Pamplona medieval y en la estructura política del reino navarro ${ }^{5}$.

Este trabajo pretende contribuir al desarrollo de estos planteamientos a través del análisis del origen social y geográfico de los canónigos pamploneses, la jerarquización interna del cabildo, las relaciones entre los capitulares y su comportamiento en los agudos conflictos internos que sacudieron a la Iglesia en este tiempo. Para ello, se ha desarrollado un estudio prosopográfico que parte de un corpus documental integrado por los fondos del Archivo de la catedral de Pamplona y los textos publicados procedentes de otras instituciones contemporáneas ${ }^{6}$. Este método permite recopilar a partir de una documentación dispersa y heterogénea todas las noticias relativas a cada personaje, identificar trayectorias vitales, estrategias individuales o modelos de acción colectiva ${ }^{7}$, ofreciendo múltiples posibilidades de análisis. Al menos, así lo reflejan los grandes proyectos europeos de investigación prosopográfica sobre el clero y algunas publicaciones recientes referidas a las instituciones catedralicias hispánicas, donde el examen de la proyección urbana de algunos cabildos, las redes clientelares o las relaciones de poder entabladas en el espacio catedralicio, han permitido determinar cuestiones como el funcionamiento del sistema de provisión de canonjías, la existencia de estrategias familiares o la incorporación de las élites locales en las instituciones religiosas ${ }^{8}$.

\footnotetext{
${ }^{4}$ Véase entre otros los trabajos compilados en: Barralis, Christine; Boudet, Jean-Patrice; Delivrè, Fabrice; Genet, Jean Philippe (dirs.), Église et État, Église ou État?, Paris-Roma, Publications de la Sorbonne-École Française de Rome, 2014.

${ }^{5}$ Encontramos un estudio que escapa de esta tendencia: Miranda García, Fermín, «Eclesiásticos al servicio de la monarquía navarra (1134-1274). Un punto de partida», en Vasconcelos Vilar, Herminia; João Branco, Maria (dirs.), Eclesiastics and political state building in the iberian monarchies, 13th15th centuries, Evora, Publicacões do Cidehus, 2016, pp. 26-42.

${ }^{6}$ Además de la documentación del Archivo Catedral de Pamplona, se han consultado las colecciones documentales publicadas procedentes del Archivo Municipal de Pamplona, la sección de Comptos del Archivo General de Navarra y los centros religiosos de Roncesvalles, Leyre, Iranzu, Irache, Fitero, la Oliva, el priorato de la Orden de San Juan de Jerusalén, Santa María de Nájera, los cartularios de San Salvador de Zaragoza, el monasterio de Montearagón y la catedral de Huesca.

${ }^{7}$ Sobre la prosopografía como método de investigación véase: Beech, George T., «Prosopography», en Powell, James M. (ed.), Medieval Studies: an Introduction, Syracuse, Universidad de Siracusa, 1979, pp. 151-184; Bulst, Neithard; Genet, Jean-Philippe (eds.), Medieval Lives and the Historian. Studies on Medieval Prosopography, Kalamazoo, Medieval Institute Publications-Western Michigan University, 1986; Genet, Jean-Philippe, «Medieval Prosopographical Research at the University of Paris I», Medieval Prosopography, 1980, 1, pp. 1-13; Millet, Hélène (ed.), Informatique et prosopographie, Paris, Centre National de la Recherche Scientifique, 1985. También como resultado de los debates surgidos al calor de los proyectos Gènese de l'État Moderne y The Origins of the Modern State, véase Narbona Vizcaíno, Rafael, «El método prosopográfico y el estudio de las élites de poder bajomedievales», en El Estado en la Baja Edad Media: nuevas perspectivas metodológicas, Zaragoza, Universidad de Zaragoza, 1999, pp. 31-49.

${ }^{8}$ Debemos mencionar el desarrollo de grandes proyectos de investigación en países como Alemania, Suiza, Inglaterra, Francia o Portugal, encaminados a la creación de bases de datos en las que recoger las biografías del clero a escala nacional, donde se ha mostrado la versatilidad de esta metodología de
} 
Los años que transcurren entre los obispados de García Ferrández (1194-1205) y Pedro Jiménez de Gazólaz (1242-1266) constituyen un periodo de intensas transformaciones en la diócesis de Pamplona que se plasmaron en el incremento de la autonomía de los canónigos respecto al poder del obispo. El hito que marcó el inicio de este proceso fue la separación de las mesas episcopal y capitular en $1177^{9}$, lo que implicó en la práctica el final de la gestión comunitaria del patrimonio catedralicio, su división en prebendas individuales y la consiguiente formación de importantes fortunas en manos de los beneficiados. Los graves conflictos que tuvieron lugar durante algunas elecciones episcopales, los años de sede vacante $o$ las disputas entre varios candidatos al obispado, saldadas a través de apelaciones a diversos tribunales eclesiásticos, sugieren que este periodo de amplio crecimiento económico contempló serias crisis internas, lo que lleva a pensar que, al igual que sucede en otras sedes, estas prebendas contribuyeron a acentuar la jerarquización interna y a convertir los altos cargos del cabildo en objetivo de las estrategias individuales y familiares de los grupos sociales que tenían capacidad para situar a algunos de sus integrantes en el entorno capitular.

Para concretar estas hipótesis se han analizado las redes sociales de las que formaron parte los miembros del cabildo pamplonés con el propósito de definir el modo en que contribuyeron a la construcción de la hegemonía social de la iglesia de Pamplona. A partir de la descripción de la estructura del capítulo, se han abordado cuestiones como el origen geográfico de los canónigos, su extracción social, el acceso a los puestos canonicales y su permanencia en ellos para calibrar la acumulación de prebendas y la jerarquización interna. Por otra parte, para explicar las relaciones entabladas entre los capitulares y los obispos en un contexto de conflictos surgidos a raíz del pulso entre la reafirmación de la autoridad episcopal y la consolidación de la autonomía creciente de los canónigos, ha sido necesario contemplar el comportamiento del grupo respecto al ejercicio del poder, la

investigación de historia social para el estudio de las élites eclesiásticas. Destacaremos el caso inglés, francés y portugués, con los proyectos Fasti Ecclesiae Anglicanae, Fasti Ecclesiae Gallicanae y Fasti Ecclesiae Portugaliae, respectivamente. Respecto a la aplicación del método para el estudio de los cabildos catedralicios hispánicos, véase entre otros: Pérez Rodríguez, Francisco Javier; González Vázquez, Marta, «Aproximación al estudio de las relaciones familiares y de poder en una institución eclesiástica: el cabildo compostelano de los siglos XII y XIII», Hispania, 1993, 59, 185, pp. 1091-1098; Nieto Soria, José Manuel; Díaz Ibáñez, Jorge, «Élites y clientelas eclesiásticas (siglos XIII al XV): propuestas metodológicas desde el caso castellano», en Themudo Barata, Filipe (coord.), Elites e redes clientelares na Idade Média, Lisboa, Colibrí, 2001, pp. 109-139; Díaz Ibáñez, Jorge, «La incorporación de la nobleza al alto clero en el reino de Castilla durante la Baja Edad Media», Anuario de estudios medievales, 2005, 5, 2, pp. 557-604; Pons Alós, Vicente, «Los canónigos de la catedral de Valencia (1375-1520). Aproximación a su prosopografía», Anuario de estudios medievales, 2005, 35, 2, pp. 907950; Guijarro González, Susana, «Jerarquía y redes sociales en la Castilla medieval: la provisión de beneficios eclesiásticos en el cabildo de la catedral de Burgos (1390-1440)», 2008, Anuario de estudios medievales, 38, 1, pp. 271-299; Conesa Soriano, Julia, «The Cathedral Chapter of Barcelona and the urban elites at the end of the fifteenth century», en Sabaté i Curull, Flocel (dir.), Life and Religion in Middle Ages, Newcastle Upon Tyne, Cambridge Scholars Publishing, 2015, pp. 234-246.

${ }^{9}$ CDCP, n. 353. 
existencia de vínculos, solidaridades o posibles parentescos, así como las fórmulas de elección y obtención de los cargos principales. Todo ello se dirige, en última instancia, a comprobar el modo en que la autonomía de una parte del clero secular terminó trastocando el sistema de dependencia que había caracterizado la organización de la Iglesia navarra, configurada durante la reforma gregoriana una centuria antes, hasta el momento en que se alcanza un nuevo equilibrio durante la segunda mitad del siglo XIII. Un aspecto cuyo interés no se circunscribe a la diócesis de Pamplona, sino que debería ser abordado desde una perspectiva más amplia para determinar, por medio de la comparación con otras sedes, la trascendencia de estos periodos críticos en la evolución de las estructuras eclesiales hispánicas.

\section{EL ORIGEN DE LOS CANÓNIGOS DE LA CATEDRAL DE PAMPLONA}

Entre 1194 y 1266 se documentan casi un centenar de canónigos simples y dignidades cuya participación en el gobierno de la diócesis es visiblemente desigual, destacando una veintena de personas con una actividad constante entre una mayoría con escasas menciones ${ }^{10}$. Los capitulares mejor documentados apuntan una media de permanencia en el cargo de veinticinco años, indicativa de una incorporación temprana al cabildo y de la prolongación de la vida capitular hasta el fallecimiento, con pocas o ninguna promoción a otras instituciones semejantes fuera del espacio navarro, y nos permite fijar en una treintena la dimensión media del cabildo a lo largo de este periodo ${ }^{11}$.

El examen de los apellidos toponímicos, presentes en más del $60 \%$ de los eclesiásticos, y el predominio de las formas vascas y romances navarras en la onomástica de aquellos clérigos que no presentan locativo o de los que desconocemos su correspondencia actual, muestra que el cabildo pamplonés estuvo constituido principalmente por religiosos navarros; ${ }^{12}$ pero esto no siempre había

\footnotetext{
${ }^{10}$ Conviene recordar los peligros de este tipo de estudios, que comprenden la posibilidad de identificar en una misma persona a más de una individualidad o desdoblar en varias personalidades a un mismo individuo. Véase Jiménez, Francisco Javier, «El cabildo pamplonés», pp. 392-393.

${ }^{11}$ En 1254, la lista más completa de la centuria señala la existencia de treinta y un religiosos en la iglesia de Pamplona. AHN, Clero, carp. 1425, n. 1. Véase García Arancón, $M^{a}$ Raquel, «El clero secular en Navarra a mediados del siglo XIII», Hispania Sacra, 1999, 51, 104, pp. 676-677 y Goñi, José, Historia de los obispos, I, 642-643. Dimensiones parecidas las encontramos en Cuenca, con 26 canónigos y 8 dignidades en el siglo XIII, o el sur de Francia, en Aviñón, Arlés o Lyon, con cabildos de unos 30 a 40 canónigos. Véase Díaz Ibáñez, Jorge, «El cabildo catedralicio conquense en el siglo XIII», Anuario de estudios medievales, 1997, 27, 1, pp. 315-346; Hidalgo Sánchez, Santiaga, «Obispo y cabildo, promotores en la Edad Media: el caso del claustro de Pamplona», Cuadernos de la Cátedra de Patrimonio y Arte Navarro, 2007, 2, pp. 279-292. El acceso temprano a las canonjías también fue planteado por Francisco Javier Jiménez para el siglo XIV en su estudio prosopográfico. Jiménez, Francisco Javier, «El cabildo pamplonés», p. 395.

${ }^{12}$ Aunque tenemos algunos ejemplos de nombres vascos, como Pedro Ezquerra (CDCP, n. 599), la mayoría de los canónigos presentan nombres romances de tipo pirenaico, y entre ellos interesan
} 
sido así. Durante el siglo XII, el asentamiento de nuevas poblaciones en el reino y la dinámica política habían propiciado la presencia de clérigos ultrapirenaicos y aragoneses tanto en el episcopado como en las filas del cabildo. Con el obispo Pedro de Roda (1083-1115), se integraron en el capítulo no menos de quince canónigos de origen franco, mientras que con el oscense Sancho de Larrosa (11221142) se intensificó la presencia aragonesa. Desde entonces, primó la diversidad y podemos encontrar capitulares franceses, aragoneses, navarros e incluso ingleses ${ }^{13}$.

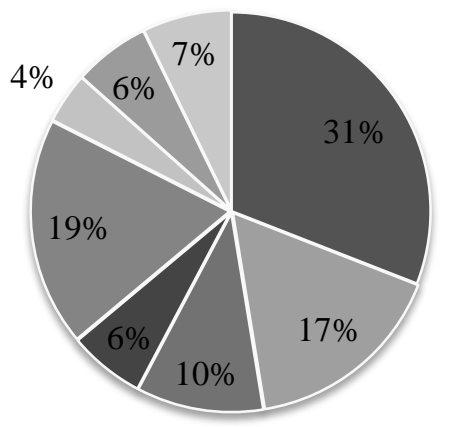

- Sin locativo
Montañas
— Estella
- Ribera
- Sangüesa
- Ultrapirenaico
Otros
Desconocido

Gráfico 1. Procedencia geográfica de los canónigos (1194-1266). (Fuente: elaboración propia)

La situación que encontramos a lo largo de la primera mitad del siglo XIII concuerda con el progresivo fortalecimiento del reino y la navarrización de sus instituciones, lo que conduce a pensar que el cisma que dividió la diócesis entre 1159 y 1164 tras la elección a la mitra episcopal de dos candidatos, uno navarro y otro aragonés, y el obispado del artajonés Pedro de París (1167-1193), debieron marcar el inicio del predominio de navarros en el capítulo de Pamplona. Esta característica corrió en paralelo a la incorporación de miembros de la nobleza o la burguesía local, a la que se hará referencia a continuación, cuya participación en algunos conflictos por el control de las principales dignidades muestra que, durante

aquellos propiamente navarros como Aznar, Eneco o Íñigo, Semén o Jimeno, García y Sancho. Como ejemplos, se pueden citar: Bernardo (CDCP, n. 414, 427 o 459), Mancio (CDCP, n. 519), Egidio (ACP, II Epi 58. Ferrando (CDCP, n. 219 y 523), García Martín (CDCP, n. 581 y 598), P. Semeniz (CDCP, n. 494), Semén Tomás (ACP, O 14), Sancho de Gueretz (CDCP, n. 519 o 573) o Íñigo de Sotirana (CDCP, n. 598, ACP, II Epi 58 y Cantoris 37, 44), entre otros. Por el contrario, los ejemplos onomástica occitana son menores y menos variados, destacando la reiteración del nombre Arnaldo: Arnaldo Bos (CDCP, n. 597), Arnaldo del Pont (CDCP, n. 494) o Guillermo Arnaldi (CDCP, n. 560). Véase Ciérbide Martinena, Ricardo, «El nombre de los navarros», en Ramírez Sádaba, José Luis (coord.), La onomástica en Navarra y su relación con la de España. Actas de las primeras jornadas de Onomástica (Pamplona, 2003), Pamplona, Universidad Pública de Navarra, 2005, pp. 15-34.

${ }^{13}$ Véase Goñi, José, Historia de los obispos, I, pp. 423-428 e Id., «Episcopado y cabildo», p. 59. 
la primera mitad del siglo XIII, la institución se convirtió en un escenario donde se manifestaron las inquietudes de las familias y linajes del reino.

Entre los capitulares ha sido posible identificar algunos miembros de la alta nobleza como Rodrigo de Subiza, hospitalero entre 1217 y $1223^{14}$, García de Urroz, canónigo simple -aunque parece desempeñar el oficio de camarero en $1236^{15}-\mathrm{y}$ Guillermo de Óriz, arcediano. Los dos primeros formaban parte de dos de los doce linajes tradicionales del reino navarro, los Subiza y los Urroz, mientras que los Óriz fueron una de las familias de barones que emergieron durante el reinado de Sancho VI el Sabio (1150-1194) ${ }^{16}$. Guillermo, arcediano de la Cámara desde 1223, se sirvió de esta dignidad para obtener una destacada posición dentro del cabildo, que le llevó a ser elegido obispo por una parte de los canónigos durante la doble elección posterior a la muerte de Pedro Remírez de Piedrola en $1230^{17}$. Aunque finalmente no accedió al episcopado, figura en octubre de 1236 firmando un acuerdo junto a sus hermanos con el cabildo de Roncesvalles que ponía fin a una querella entablada entre ellos por el control de diversas heredades en Imárcoain y Arizpelceta ${ }^{18}$. En este tiempo accedió al capítulo pamplonés Juan Garcés de Óriz, por lo que no debemos descartar la intervención del primero a favor de su incorporación. Juan permaneció en él hasta 1258, cuando el papa Alejandro IV le nombró abad de Montearagón y, tras encargar a su "familiar" Guillermo que tomara posesión del cargo en su nombre, este canónigo se convirtió en uno de los abades más importantes del centro aragonés hasta su muerte en $1284^{19}$.

Asimismo, las listas de mesnaderos recogidas en los registros de Comptos de 1259 y 1266, conservadas en el Archivo General de Navarra, permiten identificar a representantes de la baja nobleza del reino a cargo de canonicatos y dignidades en

\footnotetext{
${ }^{14}$ CDCP, n. 515, 520, 534, 546. Otros dos miembros del linaje realizaron donaciones al hospital de San Juan de Jerusalén entre 1199 y 1206, Fortunio de Subiza y Martín de Subiza. GPN, n. 101, 126 y 134. Este pleito es uno más de los que mantuvo Roncesvalles por el mantenimiento o posible ampliación de su dominio, los cuales se acentuaron en la década de 1230. Miranda García, Fermín, Roncesvalles. Trayectoria patrimonial (siglos XII-XIX), Pamplona, Gobierno de Navarra, 1993.

${ }^{15}$ CDCP, n. 591, 595, 599. Consideramos que su presencia en el cabildo fue anterior a 1236, al menos desde 1232 puesto que en este año el caballero Íñigo de Urroz realiza una donación piadosa a la tabla de los canónigos. CDCP, n. 574.

${ }^{16}$ El linaje de los Óriz emergió a lo largo del reinado de Sancho VI el Sabio, sumándose junto a otras familias a los grandes linajes tradicionales navarros. Martín Duque, Ángel Juan, «Sancho VI el Sabio y el fuero de Vitoria», Príncipe de Viana, 2002, 63, 227, pp. 773-790.

${ }^{17}$ CDCP, n. 546, 569, 591.

${ }^{18}$ CDR, n. 91. Estos son Î́nigo de Óriz, Jimeno de Óriz, Lope García de Óriz y García Arceiz de Óriz. Imárcoain se sitúa en la cuenca de Pamplona, dentro de la merindad de las Montañas, pero desconocemos la ubicación de la segunda localidad. Santos García Larragueta planteó que podía tratarse de Azpilcueta, situada al norte de la merindad de Pamplona, en el valle del Baztán, aunque quizás podría hacer referencia a la villa de Arizaleta de la merindad de Sangüesa, que formó parte del patrimonio de Roncesvalles desde finales del siglo XII. García Larragueta, Santos, «El becerro de Roncesvalles», Príncipe de Viana, 1983, 44, 168-170, pp. 111-172.

${ }^{19}$ Goñi, José, Historia de los obispos, I, pp. 225-226. Durán Gudiol, Antonio, El castillo abadía de Montearagón (siglos XII y XIII), Zaragoza, Institución Fernando el católico, 1987, pp. 165 y ss.
} 
un momento de extraordinario protagonismo de este estrato social en la vida política del reino ${ }^{20}$ : Pedro Jiménez de Gazólaz, que alcanzó el obispado en $1242^{21}$, Martín García de Andosilla ${ }^{22}$, Martín Pérez de Sarasa ${ }^{23}$, Lope Martínez de Labiano $^{24}$ y Jimeno Garceiz de Arbizu ${ }^{25}$. Junto a ellos, destacan P. Jiménez de Oarriz, probablemente miembro de una de las familias de la nobleza que habitaron los burgos de Pamplona ${ }^{26}$, Pelegrín de Eusa, que se convirtió en una figura fuerte dentro del cabildo, y Pedro Martínez de Úriz. Este último parece tener un cierto ascendiente entre sus correligionarios puesto que, tras la muerte del obispo Pedro Remírez de Piedrola en 1238, ejerció de vicario general hasta el final del siguiente año; una responsabilidad generalmente consignada al prior que, por estos años, era García de Janáriz ${ }^{27}$. Algunas de estas familias adquirieron una influencia

${ }^{20}$ Los familiares de los canónigos se mencionan en dichas listas. Son García Martínez de Úriz, Semén Martínez de Úriz, Lope Martínez de Úriz y Juan Martínez de Úriz, emparentados con Pedro Martínez de Úriz. Asimismo, se puede vincular a Jimeno Garceiz de Arbizu con Semén Garceiz de Arbizu, a Martín García de Andosilla con Gonzalo Garceiz de Andosilla, a Martín Petri de Sarasa con Remir Périz de Sarasa, a Lope Martínez de Labiano con Diego Martínez de Labiano, y a Pedro Jiménez de Gazólaz con Martín Jiménez de Gazólaz. Asimismo, encontramos en estas listas a los hermanos Pedro Garceiz de Oarriz y Miguel Garceiz de Oarriz, Pedro Pérez de Oarriz y Diego Martinez de Oarriz, y entre los Eusa a los hermanos Jimeno Garceiz de Eusa y Martín Garceiz de Eusa, a García Martínez de Eusa y a García Pérez de Eusa. Véase García Arancón, $\mathrm{M}^{\mathrm{a}}$ Raquel, Archivo General de Navarra. Sección de Comptos. Registro ${ }^{\circ} 1$ (1259 y 1266), San Sebastián, Sociedad de Estudios Vascos, 2000, pp. 121-128 e Ilundáin Chamarro, Javier, «Prosopografía de la baja nobleza navarra bajo la dinastía de Champaña (1234-1274)», Navarra: memoria e imagen. Actas del VI Congreso de Historia de Navarra. Pamplona, 2006, vol. I, Pamplona, Eunate, 2006, pp. 173-190.

${ }^{21}$ José Goñi lo identificó con un tal Pedro Jiménez, canónigo, pero la existencia de otros capitulares de nombre similar -entre ellos, Pedro Jiménez de Oarriz- impide asegurar esta hipótesis. Su presencia como canónigo es segura en 1232, cuando aparece como testigo en una compra de la Orden de San Juan de Jerusalén con su nombre completo. Goñi, José, Los obispos de Pamplona, I, p. 97 y GPN, n. 242.

${ }^{22}$ CDCP, n. 599.

${ }^{23}$ CDCP, n. 500, 534.

${ }^{24}$ CDCP, n. 599.

${ }^{25}$ CDCP, n. 595, 599, 607.

${ }^{26}$ CDCP, n. 494, 519, 558, 561. En 1244, los jurados del burgo de San Cernin donan cien sueldos al filz mayor de don Garcia Semeneitz d'Oarriz. DAMP, n.18. De igual modo, el toponímico Oarriz está entre los documentados por Eloísa Ramírez en el burgo de San Nicolás como apellidos locales entre 1200 y 1250. En 1280, los registros de Comptos recogen la confiscación a Jimeno de Oárriz de su señorío sobre Irurzun y Arraiz, junto a otros pertenecientes a otros grandes linajes de la alta nobleza, como los Baztán, los Almoravid o los Vidaurre, dentro de una política regia encaminada a recuperar las grandes villas en manos de estas familias y reducir, así, su posición en el reino. Mugueta Moreno, Íñigo, «La nobleza de Navarra (siglos XIII-XIV): una identidad militar», Iura Vasconiae, 2007, 4, pp. 208-209. Documentamos a Jimeno de Oarriz en 1197, por lo que podríamos pensar en nuestro canónigo como uno de sus descendientes, así como a García Jiménez de Oarriz, que ejerce de árbitro en 1237 para favorecer un acuerdo entre Teobaldo I y el concejo de Tudela por las tensiones establecidas entre ellos, y aparece de nuevo en 1252, intercambiando con el comendador de Cizur diversas casas, piezas y collazos en Acella. GPN, n. 93, 344 y CAGN, n. 216.

${ }^{27}$ Goñi, José, Historia de los obispos, I, 584-585. Aparece en julio de 1240 cumpliendo una donación piadosa en nombre de su padre Martín de Úriz al hospital de Roncesvalles y haciendo sepultar su 
significativa en el reino a lo largo de la centuria; es el caso de los Eusa y los Úriz, cuyo poderío económico alcanzó dimensiones similares a las de los grandes linajes de ricoshombres a mediados del siglo XIII y, mientras los primeros tuvieron un papel activo en las Juntas de infanzones de Obanos, los segundos comenzaron a ocupar una importante posición en el entorno del monarca a raíz de la guerra de $1276^{28}$. El interés de algunos miembros de ambas familias por Pamplona y su sede parece prolongarse en el siglo XIV, lo que se deduce de la presencia de dos de sus miembros en el gobierno municipal y en la catedral. En 1297 Íñigo de Úriz formó parte del Concejo de los Veinte, que regía la ciudad por aquel entonces, mientras que el apellido Eusa se repite en el siglo XIV con el canónigo, y después prior, Martín Martínez de Eusa ${ }^{29}$.

Además de los citados, llama la atención Semén López de Luna, a quien es posible relacionar con una de las ramas del linaje aragonés de los Luna. Este religioso ocupó el arcedianato de la Valdonsella, la dignidad de chantre y abad de San Miguel de Excelsis desde $1268^{30}$ y, sólo un año después, el priorato. Dos décadas más tarde siguió desempeñando esta dignidad, por lo que podemos pensar que se mantuvo en ella hasta su muerte ${ }^{31}$. La casa de Luna disfrutó en este periodo de un progresivo fortalecimiento político en Aragón encaminado a favorecer la inserción de sus miembros en los cuadros de gobierno y a desarrollar una ambiciosa red de alianzas matrimoniales para expandir su base patrimonial. Un factor decisivo en este ascenso fue el control de algunos de los puestos principales de la jerarquía eclesiástica hispánica ${ }^{32}$, por lo que no es de extrañar que el linaje se interesase por colocar a algunos de sus miembros en la organización eclesiástica navarra, dentro

cuerpo allí. El documento es firmado en el castillo de Martín de Úriz, dando una idea de la posición social de la familia. CDR, n. 107.

${ }^{28}$ CDCP, 599 y ACP, O 14 y S 18. Véase García Arancón, Ma Raquel, «Tres linajes navarros bajo la casa de Champaña», Aragón en la Edad Media, 1999, 14-15, 1, pp. 669-686, Id., «La Junta de Infanzones de Obanos hasta 1281», Príncipe de Viana, 1984, 45, 173, pp. 527-560 y Ramírez Vaquero, Eloísa, «La nobleza bajomedieval navarra. Pautas de comportamiento y actitudes políticas», en La nobleza peninsular en la Edad Media. VI Congreso de Estudios Medievales, Ávila, Fundación Sánchez Albornoz, 1997, pp. 297-324.

${ }^{29}$ Ramírez Vaquero, Eloísa, «The first urban oligarchic networks in Navarre: Pamplona, 1100-1328», en Asenjo-González, María (dir.), Oligarchy and patronage in late medieval spanish urban society, Turnhout, Brepols, 2009, pp. 117-152. García de la Borbolla, Ángeles, «La identidad de los canónigos», p. 727, nota 90.

${ }^{30}$ La chantría se combinó con el control del santuario de San Miguel de Excelsis, situado en HuarteAraquil, y que hoy se conoce como San Miguel de Aralar. De este modo, el chantre era a su vez abad de San Miguel.

${ }^{31}$ ACP, V Epi 20 y I Cantoris 73, 71. Goñi, José, Historia de los obispos, I, p. 709.

${ }^{32}$ Destacan Jimeno de Luna, obispo de Zaragoza (1296-1317), arzobispo de Tarragona (1217-1328) y de Toledo (1328-1337), Pedro López de Luna, abad de Montearagón (1306-1317), obispo y primer arzobispo de Zaragoza (1318-1345), Lope Fernández de Luna, obispo de Vic (1348-1351), arzobispo de Zaragoza (1351-1382), patriarca de Jerusalén (1382) y canciller de Pedro IV. Moxo y Montoliu, Francisco, La casa de Luna (1276-1348). Factor político y lazos de sangre en la ascensión de un linaje aragonés, Münsten, Aschendorffsche Verlagsbuchhandlung, 1990. 
de una estrategia familiar intergeneracional dirigida a mantener e incrementar la presencia política del linaje tanto en la Corona de Aragón, como en aquellas instancias con potestad sobre sus territorios. No deja de ser significativo que Semén López de Luna comenzara su carrera canonical ocupando el arcedianato que tenía bajo su control los territorios que coincidían con los límites del reino aragonés, una zona en permanente conflicto y disputa entre las diócesis de Pamplona y Huesca ${ }^{33}$.

Ciertamente, el volumen de capitulares de origen nobiliario documentados no muestra el predominio numérico que sí se ha atestiguado en el siglo $\mathrm{XIV}^{34}$, lo que hace pensar que cuestiones como la escasa representación de los linajes nobiliarios en la Pamplona medieval, el distanciamiento de la monarquía respecto de dicha ciudad o la limitada presencia del obispo y los canónigos de los círculos más próximos a la monarquía y la administración -lo que limitaba en la práctica la posibilidad de promocionar desde la sede diocesana hacia el entorno monárquico que sí se aprecia en otras sedes coetáneas- ${ }^{35}$, pudieron dirigir los intereses de la nobleza hacia otros espacios del reino. Sin embargo, ello no resta importancia a religiosos como Guillermo de Óriz, Pelegrín de Eusa o Semén López de Luna, cuyo papel en la institución y su participación activa en los conflictos más significativos del periodo evidencian un creciente interés de las parentelas nobles por afirmar su presencia en el capítulo catedralicio.

Dicho esto, si examinamos la relación de los canónigos con las élites de la Pamplona medieval, los datos recogidos y la información aportada por los estudios prosopográficos más recientes permiten conjeturar la existencia de canónigos con vínculos familiares con miembros del patriciado urbano, familias de la burguesía y la nobleza local que ocuparon puestos de responsabilidad en el gobierno de los burgos. Aunque es difícil ser taxativos, se puede plantear el parentesco de P. de Zabalza, subprior en 1218, y Juan de Zabalza, jurado de San Saturnino en 1244, de Pedro Simeón, arcediano de la Tabla entre 1197 y 1206, y Simón Pérez, jurado de San Nicolás en 1255, o de Semén Tomás, canónigo en 1253, y Juan Tomás, jurado de Navarrería en 1266.

Entre los miembros de la burguesía local identificados entre los canónigos destacan dos pertenecientes a familias dedicadas al comercio local y al cambio:

\footnotetext{
${ }^{33}$ Se trata del territorio de las Cinco Villas, al este del reino de Navarra. Sobre este espacio como zona de conflicto, véase Abella Samitier, Juan, «La comarca de la Valdonsella en las relaciones entre Aragón y Navarra a fines de la Edad Media», Príncipe de Viana, 2011, 72, 253, pp. 335-348.

${ }_{34}$ Jiménez, Francisco Javier, «El cabildo pamplonés», pp. 398-399 y p. 403. Frente a los más de noventa canónigos de origen nobiliario que identifica este autor a lo largo de un siglo, solo hemos podido identificar once en estas siete décadas.

${ }^{35}$ Ramírez Vaquero, Eloísa «The elites of Pamplona at the end of the Middle Ages: the road to ennoblement», en Asenjo González, María (ed.), Urban elites and aristocratic behaviour in the spanish kingdoms at the end of the Middle Ages, Turnhout, Brepols, 2013, pp. 61-85; Miranda, Fermín, «Eclesiásticos al servicio de la monarquía navarra», p. 42; Vasconcelos Vilar, Herminia, «Les clerici regis et le service du roi dans le Portugal des XIII ${ }^{\mathrm{e}}$ et XIV ${ }^{\mathrm{e}}$ siècles», en Barralis, Christine; Boudet, Jean-Patrice; Delivrè, Fabrice; Genet, Jean-Philippe (dirs.), Église et État, pp. 153-156.
} 
Tomás de Rosas, quien aparece como canónigo en 1218, y algunos miembros de la familia Bos ${ }^{36}$. Los Rosas residieron en los burgos de San Saturnino y San Nicolás desde mediados del siglo XIII y se convirtieron en la primera mitad del siglo XIV en una de las principales familias de mercaderes pamploneses, lo que favoreció el acceso de sus integrantes a los órganos de gobierno local ${ }^{37}$. Entretanto, los Bos se documentan en el burgo de San Nicolás entre 1200 y 1249, coincidiendo cronológicamente con su presencia en el cabildo pamplonés. El primer vínculo de esta familia con la catedral se fecha en junio de 1216 con Arnaldo Bos, cuyo padre, Bos, actuó de testigo en varias transacciones realizadas en 1199 entre algunos miembros de la burguesía local y el obispo García Ferrández ${ }^{38}$. Durante este tiempo, Arnaldo disfrutó de dos arcedianatos, el de Estella, primero, y el de Urroz desde 1223, hasta que en julio de 1230 ocupó el cargo de chantre (en el que se mantuvo hasta 1249) y coadjutor del prior Lope de Laguardia durante el periodo de sede vacante (1228-1230) ${ }^{39}$. En 1238 accedió al cabildo otro miembro de esta familia, Pedro Bos de Pamplona, y se mantuvo como canónigo simple al menos hasta 1254, sin ostentar ningún cargo relevante ${ }^{40}$. Todo ello sugiere el similar interés de estas élites por vincularse con el cabildo pamplonés y el modo en que la institución sirvió de plataforma de promoción familiar a través del acceso de algunos de sus miembros a sus canonjías y dignidades.

El ejemplo de los Bos pone de manifiesto la existencia de vínculos familiares en el seno del cabildo, pero no es el único caso documentado, lo que ha permitido conocer la frecuencia con la que las solidaridades internas del clero pamplonés

\footnotetext{
${ }^{36}$ CDCP, n. 519. Ramírez Vaquero, Eloísa, «The first urban oligarchic networks», 137. El caso de la familia Bos es menos conocido; sin embargo, se pueden deducir sus relaciones con otros miembros de la burguesía local a raíz de una serie de documentos de 1199 conservados en el archivo catedralicio, en los cuales Bos actuó como testigo junto a otros burgueses de Pamplona -varios mercaderes, un cambista y un peletero-, y de algunos miembros de los concejos de los burgos documentados por Eloísa Ramírez en el trabajo citado, como J. Bon Amic, alcalde de San Nicolás en 1200 o P. de Garín, CDCP, n. 427, 428, 429, 432, 477. De otros testigos, como Miguel de Jaca, conocemos su poder adquisitivo gracias a una donación piadosa al cabildo emprendida en su nombre por sus hijos en 1253, uno de ellos amirat del burgo de San Cernin. ACP, O 14.

${ }^{37}$ Ramírez Vaquero, Eloísa, «The first urban oligarchic networks», 142-143. Ortí de Rosas formó parte del Concejo de los Veinte en 1273, mientras que Caritat de Rosas integró el concejo de San Nicolás en 1287 y el de los Veinte en 1297. Ibid., pp. 148-149. Véase también Carrasco Pérez, Juan, «Sociedades mercantiles en los espacios urbanos del camino de Santiago (1252-1425): de San Juan de Pie de Puerto a Burgos», Las sociedades urbanas en la España medieval, XXIX Semana de Estudios Medievales de Estella, Pamplona, Gobierno de Navarra, 2003, pp. 243-276. La Pamplona medieval estaba integrada en el siglo XIII por tres burgos con sus instituciones de gobierno propias: la ciudad de la Navarrería -el núcleo urbano originario, el burgo de San Cernin o San Saturnino y la Población de San Nicolás, surgidas al calor de las migraciones del siglo XII. En 1287, nacerá temporalmente el Concejo de los Veinte, resultado de la unión de los concejos del burgo de San Saturnino y la Población de San Nicolás: Irurita Lusarreta, $\mathrm{M}^{\mathrm{a}}$ Ángeles, El municipio de Pamplona en la Edad Media, Pamplona, Ayuntamiento de Pamplona, 1959.

${ }^{38}$ CDCP, n. 427, 428, 429.

${ }^{39}$ CDCP, n. 506, 523, 546, 567. ACP, Episcopi VI, 47.

${ }^{40}$ CDCP, n. 599. ACP, O 15.
} 
descansaron sobre vínculos de consanguineidad y actuaron como pilar para el acceso y la promoción interna de los canónigos ${ }^{41}$. Así, es posible citar a Pedro Arceiz de Leoz, canónigo entre 1237 y 1255, Adán de Arceiz, que desde 1295 comienza a ocupar diferentes dignidades, y Martín Sánchiz de Arceiz, activo desde $1326^{42}$. Aunque sabemos poco de esta familia, su presencia en los listados de las oligarquías locales y el hecho de que en este tiempo uno de los miembros del concejo de la Navarrería sea Pedro Arceiz de Zabaldica, permite enlazar a estos religiosos con el patriciado pamplonés ${ }^{43}$. En segundo lugar, destacan otros tres religiosos que participaron en algunos de los conflictos más importantes de la centuria; se trata de Guillermo de Leoz, arcediano en 1201 y prior desde 1206 a 1209, Jimeno de Leoz, enfermero en 1202 y arcediano de Urroz entre 1218 y 1223, y Pedro de Leoz, quien acumuló la enfermería y el arcedianato de la Cámara entre al menos 1215 y $1223^{44}$. El ultimo caso es el de Romeo de Gazólaz y el obispo Pedro Jiménez de Gazólaz. Romeo aparece por primera vez en 1254, por lo que probablemente accedió al canonicato promovido por su familiar, obispo de Pamplona desde 1242. Pocos años después, obtuvo el arcedianato de la Cámara, conservando la dignidad hasta la década de $1270^{45}$.

En definitiva, el origen social y geográfico de los canónigos, la existencia de vínculos de parentesco en el cabildo y el modo en que algunos capitulares trataron de pactar la introducción de sus familiares en la institución, fuese como canónigos simples o en las prebendas inferiores, con la intención de mejorar su posición en los años sucesivos, evidencian el interés de familias importantes a escala del reino por incorporarse al concreto espacio de poder que constituyó la iglesia de Pamplona. El desarrollo cultural y económico de la sede en este tiempo, la creciente autonomía del cabildo tras la división de las rentas catedralicias, la creación de nuevas dignidades y el enriquecimiento de las prebendas asociadas a las mismas contribuyeron sin duda a presentar la institución como un atractivo ámbito de promoción social entre la nobleza y la burguesía local, no sólo de forma individual sino también como parte de estrategias familiares más amplias.

\footnotetext{
${ }^{41}$ Dado que la filiación realizada se basa en la onomástica, no se debe descartar una posible relación de estos tres religiosos con Pedro Arceiz de Leoz. Esto se aprecia también en otros cabildos peninsulares; véase al respecto Rodriguez Llopis, Miguel; García Díaz, Isabel, Iglesia y sociedad feudal: el cabildo de la catedral de Murcia en la Baja Edad Media, Murcia, Universidad de Murcia, 1994, p. 94.

${ }^{42}$ CDCP, n. 595, ACP, O d14. Para el siglo XIV, véase García de la Borbolla, A., «La identidad de los canónigos», pp. 718-719. La autora lo transcribe como Arteiz.

${ }^{43}$ Ramírez Vaquero, Eloísa, «The first urban oligarchic networks», pp. 142 y 146.

${ }^{44}$ Para Pedro de Leoz, véase entre otros CDCP, n. 500,509, 546, 608. Para Jimeno de Leoz, CDCP, n. 467, 519, 523. Guillermo de Leoz en CDCP, n. 459, 474, entre otros.

${ }^{45}$ ACP, Cámara 34, 31, 01. Goñi, José, Historia de los obispos, I, p.152 y pp. 141-142.
} 


\section{JERARQUÍA Y ORGANIZACIÓN INTERNA: CARRERAS CANONICALES Y ACCESO A LAS PRINCIPALES DIGNIDADES}

En las décadas finales del siglo XII, y en especial a lo largo del Doscientos, el crecimiento económico de la catedral de Pamplona propició la creación de nuevas dignidades en el seno del cabildo que se unieron a las ya existentes, de tal manera que la lista pasó a comprender las de prior, chantre, hospitalero, enfermero, sacristán o tesorero, así como los arcedianatos de la Tabla, la Cámara, Valdonsella, Santa Gema, San Pedro de Usún, Eguiarte, Valdeaibar y Valdizarbe ${ }^{46}$. Es difícil asignar con precisión los límites jurisdiccionales de todos los arcedianatos que integraron el cabildo; el de la Tabla tenía el control sobre la Población de San Nicolás y posiblemente sobre el arciprestazgo de la cuenca de Pamplona, el de la Valdonsella se extendía territorialmente por la zona de las Cinco Villas y los territorios del reino de Aragón que formaban parte de la diócesis pamplonesa, y probablemente el de la Cámara controló el arciprestazgo de Orba, el de San Pedro de Usún el de Lónguida, Santa Gema el valle de Berrueza, y el de Eguiarte el valle de Yerri ${ }^{47}$. Respecto a las nuevas dignidades, José Goñi atribuyó al obispo Juan de Tarazona (1205-1211) la creación de la chantría en 1206, encargada de la dirección del coro y asociada a San Miguel de Excelsis ${ }^{48}$, así como la transformación del oficio de camarero en el arcedianato de la Cámara a expensas de la entrega de una serie de rentas que hasta el momento habían formado parte de la mesa episcopal ${ }^{49}$. Asimismo, se documenta en este tiempo el priorato de Velate y la existencia desde 1252 de la oficina de la pitancería, responsable del sostenimiento de las capellanías y aniversarios legados a la catedral ${ }^{50}$.

\footnotetext{
${ }^{46}$ Autores como José Goñi Gaztambide y Ángeles García de la Borbolla no incluyen en las obras citadas en anteriores notas el arcedianato de Valdizarbe, mientras que Luis Javier Fortún suprime de la lista el de Valdeaibar. En la documentación aparecen ambos, el primero en una ocasión y el segundo en cuatro, por lo que creemos que ambos existieron. Véase Fortún Pérez de Ciriza, Luis Javier, «Organización eclesiástica», en Martin Duque, Ángel Juan (dir.), Gran Atlas de Navarra, II, Pamplona, Caja de Ahorros de Navarra, 1986, pp. 138-143. En la documentación se mencionan también los arcedianatos de Urroz y de Estella, pero consideramos que hacen referencia a dos de los arcedianatos citados en el texto, con control sobre espacios al norte y al oeste del reino. Los arcedianatos de la Tabla y la Valdonsella, conocidos respectivamente como "de Pamplona” y "de Aragón” por las circunscripciones que tenían a su cargo, revelan que la existencia de un segundo nombre inspirado en el territorio al que se adscribe cada dignidad era usual. El arcedianato de Urroz estuvo ocupado por Jimeno de Leoz al menos entre 1218 y 1220, y por Arnaldo Bos desde entonces hasta la década siguiente. CDCP, n. 519, 523, 546. Para el arcedianato de Estella, véase CDCP, 523, 546, 569, 598.

47 Véase García Arancón, $\mathrm{M}^{\mathrm{a}}$ Raquel, «El clero secular en Navarra» y Fortún, Luis Javier, «Organización eclesiástica», p. 138-143.

${ }^{48}$ CDCP, n. 476. Véase Goñi, José, Historia de los obispos, I, p. 529.

${ }^{49}$ CDCP, n. 473. El primero que ocupó este cargo fue Lope de Tafalla, quien entre 1199 y 1202 es identificado como arcediano y, ya en 1207, como arcediano de la Cámara. CDCP, n. 435, 428, 429, 435, 467, 480.

${ }^{50}$ El priorato de Velate es mencionado por primera vez en junio de 1234, controlada por Martín de Cáseda al menos hasta 1241. CDCP, n. 581, 599, 608. Por otra parte, la oficina de la pitancería se
} 
Pese a la ausencia de estatutos capitulares entre 1194 y 1266, el estudio de las trayectorias individuales ha permitido iluminar las grandes líneas del cursus honorum capitular. Este análisis sugiere que la chantría, el arcedianato de la Tabla y el priorazgo constituyeron los escalones más elevados de las carreras canonicales, si bien los dos últimos tenían una dotación económica y un prestigio particulares como cabeza del cabildo ${ }^{51}$. Pese a sus diferencias en duración y número de cargos ocupados, la promoción se paralizaba al obtener uno de estos tres beneficios y, así, frente a religiosos como Pedro de Navaz y Lope Sánchez de Góngora, quienes accedieron a la chantría y al priorato desde el canonicato simple ${ }^{52}$, otros capitulares como Arnaldo Bos, Pelegrín de Eusa y Semén López de Luna prolongaron su itinerario en el cabildo durante más tiempo, debiendo controlar varios arcedianatos antes de obtener las dignidades de chantre, arcediano de la Tabla y prior, respectivamente ${ }^{53}$. Como es lógico, la mitra episcopal constituyó la meta final de la carrera eclesiástica para estos canónigos, a la que tuvieron acceso desde el cabildo pamplonés Juan de Tarazona, Pedro Jiménez de Gazólaz y Miguel Périz de Legaria. El primero, abad de San Miguel de Excelsis desde 1190 y arcediano de la Tabla desde 1197, fue obispo entre 1205 y 1211. El segundo se documenta en 1232 como canónigo, pero será en 1242 cuando acceda al obispado, mientras que el tercero, obispo desde 1288 , lo encontramos en la tesorería veinte años antes, en $1267^{54}$.

documenta en 1252, cuando García de Laquidain y su mujer María entregan al canónigo pitancero y al prior unas heredades para mantener un capellán y un aniversario. ACP, Q 7. En 1255, el cargo aparece en manos de Semén de Cuicuillo. ACP, S 18.

${ }^{51}$ Esto se deduce de la carrera de Juan de Tarazona, abad de San Miguel de Excelsis en torno a 1190 y arcediano de la Tabla en 1197, quien parece que acumuló ambos cargos, puesto que en 1199 vuelve a aparecer como abad de San Miguel. CDCP, n. 392, 408, 421. También se observa en el caso de Semén López de Luna. Arcediano de la Valdonsella desde 1247 y chantre y abad de San Miguel de Excelsis desde al menos 1268, dejó esta dignidad para ocupar el priorazgo un año después. ACP, V Epi 20. DAMP, n. 61y CCP, n. 676. Véase también Goñi, José, Los priores de la catedral, pp. 29-31.

${ }^{52}$ Pedro de Navaz, pasa de canónigo simple a chantre y abad de San Miguel de Excelsis entre 1204 y 1206. CDCP, 471, 477. Lope Sánchez de Góngora, de canónigo simple a prior entre 1238 y 1253. CDCP, 599 y ACP, O 14. Entre los que accedieron desde algún arcedianato a alguna de estas tres dignidades, Íñigo de Sotirana pasó del arcedianato de Santa Gema a la chantría entre 1235 y 1249. CDCP, n. 585 y CCP, n. 568; Guillermo de Leoz, del mismo arcedianato al priorazgo entre 1201 y 1206. CDCP, n. 459, 474; y Martín Pérez, del arcedianato de Santa Gema al de la Tabla, entre ca. 1199 y 1216. CDCP, n. 430, 504.

53 Arnaldo Bos pasó entre 1216 y 1230 por el arcedianato de Estella y el de Urroz hasta alcanzar la chantría y el control de San Miguel de Excelsis. CDCP, n. 506, 523, 546, 567. Pelegrín de Eusa, arcediano de Valdeaibar y sacrista entre 1238 y 1254, fue nombrado prior ese año, pero al parecer renunció al cargo a favor del arcedianato de la Tabla. CDCP, n. 599. ACP, O 14 y S 18. DAMP, n. 59. Para el caso de Semén López de Luna, véase nota 51.

${ }^{54}$ Para Juan de Tarazona y Pedro Jiménez de Gazólaz, véase notas 20 y 51. Para Miguel Périz de Legaria, ACP, V EPI 1, lib. 524, fol. 337 y Domínguez Sánchez, Santiago, Documentos de Nicolás IV (1288-1292) referentes a España, León, Universidad de León, 2009, n. 31. Véase también Goñi, José, Historia de los obispos, I, pp. 707-754. 


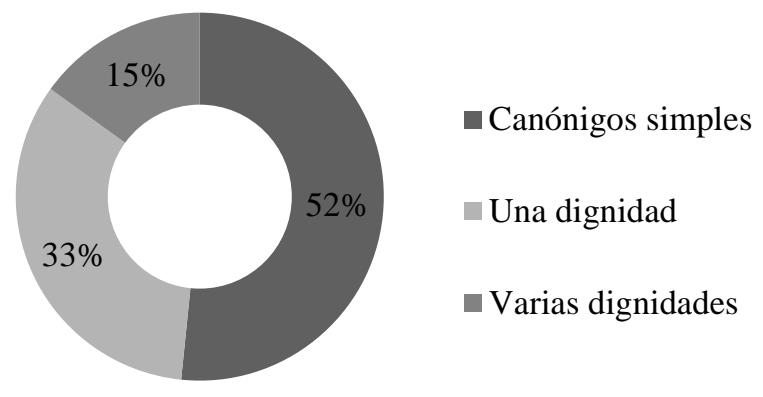

Gráfico 2: Balance de cargos ocupados (Fuente: elaboración propia)

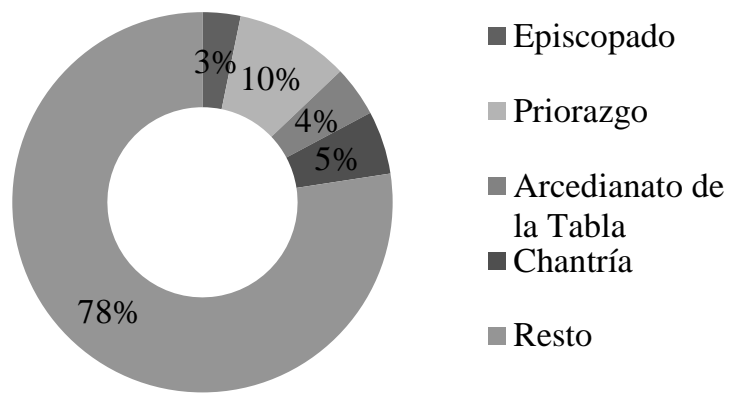

Gráfico 3: Acceso a las principales dignidades y el episcopado (fuente: elaboración propia)

Este esquema jerárquico coincide con la imagen general que apunta la documentación administrativa de la catedral. Hasta 1218, el obispo había aparecido de manera casi constante en las transacciones del prior, el arcediano de la Tabla y el convento catedralicio, así como en la gestión que se llevaba a cabo desde la chantría de los collazos o campesinos dependientes y del patrimonio de San Miguel de Excelsis. No obstante, en el transcurso de estos dos tercios de siglo, episcopado y cabildo comienzan a encabezar de forma independiente las cesiones, arrendamientos y permutas de sus propias mesas, destacando el acentuado protagonismo del prior y el arcediano de la Tabla en la gestión de la mesa capitular, y del chantre en las propiedades bajo su control. Todo ello confirma la creciente autonomía de los canónigos, su progresivo distanciamiento de la figura episcopal y la separación definitiva en la gestión de una parte significativa del dominio e iglesias de la diócesis entre las dos entidades citadas y, dentro del grupo canonical, entre los diferentes cargos ${ }^{55}$.

${ }^{55}$ CDCP, n. 468, 479, 510, 518, entre otros. 
Finalmente, la intensa actividad del arcediano de la Tabla Martín Pérez, cuya presencia es constante entre 1211 y 1244, unida a los conflictos que rodean a este arcedianato, corrobora de la idea de que ésta constituyó una de las más altas dignidades de la institución ${ }^{56}$. Además de controlar la administración de las rentas adscritas al cargo y de percibir junto al prior las donaciones a la catedral, su dimensión política se refleja en la aparición de un personal de servicio y escolta que parece rodear al arcediano y cuyas dimensiones exactas desconocemos ${ }^{57}$. Este testimonio permite comprobar que la consolidación de los vínculos entre la jerarquía eclesiástica de la sede pamplonesa y las élites del reino se materializó no solo a través del ingreso de sus miembros en el estamento eclesiástico, sino también en el establecimiento de lazos de vasallaje entre ellos, concretados en el mantenimiento por parte de los obispos y del propio cabildo de pequeños grupos de escuderos que se conformaron como verdaderos séquitos militares ${ }^{58}$. La existencia de “casas” propias de los altos cargos eclesiásticos no era extraña en la época y en varias ocasiones se ha puesto de manifiesto su existencia como forma de exteriorizar su capacidad de coacción y hegemonía social ${ }^{59}$. Sin embargo, en el tiempo y espacio que aquí analizamos, solo el obispo Pedro Ximénez de Gazólaz y -fuera de la diócesis, pero con un vínculo con la catedral pamplonesa- el abad de Montearagón y antiguo canónigo de Pamplona Juan Garcés de Óriz participaron de esta práctica ${ }^{60}$, lo que permite pensar que este arcediano se hallaba en una situación semejante a la de la más alta jerarquía del cabildo pamplonés.

\footnotetext{
${ }^{56}$ Aparece en más de una veintena de documentos, véase entre ellos: CDCP, n. 546, 585, 598, 607, 610. ACP, Tabla 13.

${ }^{57}$ En 1227, diez años después de su acceso al arcedianato, su escudero Martín de Azterain es testigo en una donación piadosa a la catedral. CDCP, n. 560. A mediados de siglo encontramos a un canónigo de similar onomástica, Martín Pérez de Azterain, entre los partidarios del acceso de Pelegrín de Eusa al arcedianato de la Tabla. Aunque no podemos confirmar el vínculo entre ambos individuos, no debemos descartar que se trate de un familiar del escudero. En 1238, se documenta el personal de servicio con Raimundo famulo archidiacono mense, CDCP, n. 599.

${ }^{58}$ Esta misma dinámica parece responder a una práctica usual en la época. Véase Rodríguez, Miguel; García, Isabel, Iglesia y sociedad feudal, pp. 50-51.

${ }^{59}$ Laliena Corbera, Carlos, «La administración de un patrimonio eclesiástico. El libro contable del obispo de Huesca Guillem Ponç de Fenollet (1463)», Aragón en la Edad Media, 1987, 7, pp. 151-176. Rodríguez, Miguel; García, Isabel, Iglesia y sociedad feudal, pp. 50-51.

${ }^{60}$ El caso del obispo de Pamplona se documenta en 1250, cuando nombra a su escudero Fortún de Larraga procurador encargado de tomar posesión de unas heredades adquiridas al monasterio de la Oliva. CDO, n. 111. Por otra parte, la casa abacial de Juan Garcés de Óriz se conoce gracias a su testamento, donde nombra además de escuderos y personal de servicio, los cargos de cocinero, acemillero, vigilante o capellán. Se conocen los nombres de dos escuderos, Lope Íñiguez y García Pérez, quienes parecen compartir con el abad su origen navarro. De ser así, podemos pensar que el abad mantuvo unos vínculos de dependencia estables que se trasladaron del reino navarro a la abadía aragonesa. Véase Durán, Antonio, El castillo abadía, pp. 201-203.
} 


\section{ENFRENTAMIENTOS Y RUPTURA DE LA JERARQUÍA ECLESIÁSTICA: PROMOCIONES FRUSTRADAS Y DISPUTAS CON EL EPISCOPADO}

El acceso al canonicato simple en Pamplona fue hasta el último tercio del siglo XIV una decisión conjunta del obispo y el cabildo, mientras que la adjudicación de dignidades estaba repartida entre ambas instancias. Esta división de funciones constituyó el germen de toda una suerte de conflictos, en tanto que la afinidad de los canónigos hacia el obispo o hacia sus correligionarios condicionaba, en la práctica, la obtención de las dignidades más codiciadas; de ahí que fuera necesario dejar claras las prerrogativas de episcopado y cabildo a finales del siglo XIII ${ }^{61}$. En esta tesitura, los intereses contrapuestos de los capitulares se plasman en los largos periodos de sede vacante, en la frustración de algunas elecciones episcopales y en las disputas con motivo del acceso a las principales dignidades, si bien el conflicto de mayor expresión fue la destitución del obispo Juan de Tarazona en 1211.

El fallecimiento del obispo es el momento en el que afloran con más facilidad las tensiones entre los canónigos al ponerse en juego las preocupaciones y expectativas personales y familiares de cada religioso. Las discrepancias de los capitulares convirtieron las elecciones episcopales en un asunto político de primer orden, dando un total de cuatro ocasiones en las que los priores -con la excepción del periodo de vicaría general del caballero Pedro Martínez de Úriz- ejercieron el gobierno de la diócesis por un tiempo relativamente amplio, como consecuencia de la imposibilidad de elegir un obispo o por los trámites judiciales derivados de las elecciones disputadas: Pedro Sánchez (1209-1212) ${ }^{62}$, Lope de Laguardia (1228$1230)^{63}$, Pedro Martínez de Úriz y García de Janáriz (1238-1242) ${ }^{64}$ y Lope Sánchez de Góngora (1266-1268). ${ }^{65}$

Entre todos ellos, destacan dos momentos especialmente problemáticos. El primero surgió a raíz de una doble elección en la que el cabildo dividido escogió simultáneamente al canónigo Lope García y al arcediano Guillermo de Óriz como sucesores del obispo Pedro Remírez de Piedrola $(1230-1238)^{66}$. De Lope García sólo sabemos que ocupó un canonicato simple, mientras que el segundo, arcediano

\footnotetext{
${ }^{61}$ Los estatutos dados por el obispo Miguel Périz de Legaria en torno a 1296 contemplan este reparto, y señalan como prerrogativa del obispo la entrega de los arcedianatos de Santa Gema, Valdeaibar, Eguiarte, Usún, la Valdonsella, la chantría, la tesorería, la hospitalería, y el priorato de Velate, mientras que era decisión del cabildo disposición del priorazgo, la enfermería y los arcedianatos de la Tabla y la Cámara. Cabría considerar la posibilidad de que la práctica fuera diferente. Véase Goñi, José, «Episcopado y cabildo», p. 59.

${ }^{62}$ CDCP, n. 486, 489, 491. Véase también Goñi, José, Historia de los obispos, I, pp. 533-540.

${ }^{63} \mathrm{CDCP}$, n. 567. Véase también Goñi, José, Historia de los obispos, I, pp. 567-569.

${ }^{64}$ CDCP, n. 602, 608, 609. Véase también Goñi, José, Historia de los obispos, I, pp. 585-588.

${ }^{65}$ ACP, V Epi 1, lib, 524, fol. 337. Véase Goñi, José, Historia de los obispos, I, pp. 648-651.

${ }^{66}$ No es la primera vez que sucedía; a mediados del siglo XII, la muerte del obispo Lope de Artajona (1142-1159) enfrentó a los canónigos en una doble elección episcopal tras el nombramiento como sucesores de Sancho, hijo de Sancho III de Navarra, y Pedro, de origen aragonés. Goñi, José, Historia de los obispos, I, pp. 423-428.
} 
de la Cámara en estos años, formaba parte de uno de los linajes nobiliarios del reino. Finalmente, ambas candidaturas fueron anuladas por Gregorio IX, dejando el asunto de la elección episcopal en manos de los arzobispados de Tarragona y Toledo $^{67}$. El segundo conflicto se produjo en 1266, cuando tras la muerte de Pedro Jiménez de Gazólaz el arcediano de la Tabla Pelegrín de Eusa vio entorpecida su candidatura a la mitra episcopal por la oposición de dos canónigos, Raimundo Guillermo y Juan Pérez, que apelaron la elección a la Santa Sede y denunciaron su incapacidad para controlar el obispado acusándole de iletrado ${ }^{68}$. La propuesta para el cargo revela que Pelegrín se había convertido en una figura fuerte entre sus correligionarios $\mathrm{y}$, como parte de una familia de la nobleza de gran poder económico, no es de extrañar que ambicionara el episcopado, como tampoco lo son las reservas de otros canónigos. Éstas ya habían perjudicado su carrera cuando en 1254, y tras ocupar el arcedianato de Valdeaibar, la sacristía y el priorazgo, el arzobispo de Tarragona y su delegado Hispano, arcediano de Zaragoza, intervinieron para impedir que obtuviera el arcedianato de la Tabla. El resultado de esta controversia fue la excomunión de Pelegrín y de otros diez capitulares, destacando entre ellos Semén López de Luna, Iñigo de Sotirana o Martín Pérez de Azterain ${ }^{69}$. Además de las graves implicaciones espirituales y morales que la excomunión implicaba en este tiempo, y la convulsión social que sin duda generó en la diócesis, este episodio revela la existencia de redes clientelares bien definidas dentro del cabildo que fueron más allá de los vínculos sanguíneos para configurar unos lazos de parentesco ficticios entre sus miembros similares a los que se perciben en otras instituciones catedralicias. Pelegrín de Eusa articuló en torno a sí a un tercio del cabildo, conformando un bloque que le sirvió para favorecer su promoción interna y sobre el que posiblemente sustentó sus pretensiones a la

\footnotetext{
${ }^{67}$ José Goñi relacionó este conflicto con las tensas relaciones entre la iglesia de Pamplona y el monarca Teobaldo I, causadas por el control del dominio temporal de la iglesia de Pamplona, e identificó dos partidos: el encabezado por Guillermo de Óriz, adepto a la corona y a una política de condescendencia, y aquellos que estaban frente a él. Goñi, José, Historia de los obispos, I, pp. 586-587. Si bien la política de intervencionismo regio no parece tan notable en la sede pamplonesa como en otras sedes contemporáneas, había permitido la obtención de la mitra al infante Remiro, hijo de Sancho VII, en 1220; en Castilla, por ejemplo, la monarquía fue capaz de ejercer un control cada vez mayor de la provisión del episcopado y asegurarse así la fidelidad de uno de los principales puestos de la jerarquía eclesiástica. Estas iniciativas se relacionan con las teorías políticas que dominaron los siglos XIII y XIV, donde se contemplaba la idea del poder incuestionable del monarca sobre la totalidad del reino, incluyendo en ese todo a la Iglesia. Véase Nieto Soria, José Manuel, Iglesia y poder real en Castilla. El episcopado, 1250-1350, Madrid, Universidad Complutense, 1988.

${ }^{68}$ Domínguez Sánchez, Santiago, Documentos de Clemente IV (1265-1268) referentes a España, León, Universidad de León, 1996, n. 147. Véase también Goñi, José, Historia de los obispos, I, pp. 648-649.

${ }^{69}$ El resto de canónigos son Raimundo de Estella, Semén Tomás, Juan Pérez de Falces, Jimeno López de Novallis, el hospitalero E. Ibáñez, García Pérez de Estella, Pedro Ferrández -que quizá podamos identificar con Pedro Ferrández de Tajonar, canónigo en 1238. CDCP, n. 599- y Martín Guerra. DAMP, n. 59.
} 
mitra $^{70}$, y tuvo que hacer frente a la oposición de un grupo de canónigos, cuyas dimensiones se desconocen, con influencia suficiente para cuestionar su acceso al arcedianato de la Tabla, excomulgar a sus afines y evitar unos años después la culminación de su carrera canonical con la obtención de silla episcopal. Es necesario pensar que una agresión de esta naturaleza -la privación de la comunión, que impedía la celebración de misas- dentro del cabildo tenía que dejar huellas duraderas en una institución caracterizada por la inmediatez entre sus componentes, que acudían periódicamente a orar juntos a la catedral y residían en una ciudad pequeña, donde la proximidad personal era la norma.

Este tipo de crisis responden a una época en la que los cauces institucionales para el acceso al episcopado estaban todavía bastante abiertos y forman parte de una conflictividad relativamente común en los cabildos catedralicios, pero ello no resta importancia a la división entre los canónigos que se evidencia en la formación de partidos durante las elecciones episcopales, y en el establecimiento de vínculos personales entre los canónigos y los obispos electos. Unos vínculos que, a juzgar por las consecuencias del segundo de los conflictos, se tornan especialmente activos a la hora de definir, promover o frenar el acceso a las altas dignidades de la iglesia de Pamplona.

La conflictividad no sólo afectó a las relaciones entre los canónigos, sino también al entendimiento entre los capitulares y el obispo. Los límites de la colaboración entre ambas instancias de poder habían saltado en 1151, cuando algunos canónigos mostraron su descontento hacia el obispo Lope de Artajona (1142-1159) y le acusaron de disponer de la cillería, la cámara, la enfermería y la hospitalería sin tener en cuenta al cabildo, de arrebatarles honores, de conceder dignidades de forma unilateral y de entregar heredades del capítulo a laicos, a lo que el obispo respondió acusándoles de romper la disciplina regular y dictando su excomunión. Finalmente, el arbitraje de los obispos de Bayona y Barcelona en enero de 1152 validó las dignidades concedidas sin beneplácito del cabildo y mandó restituir a los canónigos los bienes donados por el obispo y sus honores, debiéndose retractar de las injurias interpuestas ${ }^{71}$. El descontento mostrado por los canónigos, calificado por José Goñi como rebelión, parece más bien el resultado de una serie de intereses individuales que habían llevado al obispo a despojar a algunos capitulares de sus cargos y a colocar a otros religiosos afines en su lugar. A mediados del siglo XII, el capítulo canonical podía protestar, pero los cauces institucionales que podían facilitar su ataque no existían todavía. Incluso a pesar de que Roma jugaba ya un papel significativo en la resolución de los problemas internos, su capacidad disciplinaria era todavía limitada y los mecanismos de

\footnotetext{
${ }^{70}$ Entendemos que esta red tuvo que hacerse extensiva a otros de los canónigos que formaron parte de ella en sus respectivas carreras eclesiásticas. Por ejemplo, mientras Pelegrín ocupó el arcedianato de la Tabla, Semén López de Luna accedió a la chantría y solo un año después al priorazgo. ACP, I Cantoris 37, 71 y VI Episcopi 47. DAMP, n. 61.

${ }^{71}$ Goñi, José, Historia de los obispos, I, pp. 391-396.
} 
delegación del poder para resolver estas cuestiones, embrionarios. Sin embargo, en la segunda década del siglo XIII ocurría justamente lo contrario; los canónigos podían apelar al papado y conseguir que se realizasen investigaciones pormenorizadas por parte de jueces eclesiásticos habilitados que, además, solían ser autoridades próximas a los afectados, de modo que conocían el trasfondo de las disputas o podían llegar a un conocimiento razonable. Además, el avance de la eficacia del Derecho canónico permitió que las acusaciones tuvieran lugar en escenarios públicos y mediante testimonios escritos, lo que impedía que los debates quedasen ocultos entre bastidores.

En el periodo analizado, las tensiones entre obispado y cabildo alcanzaron su máxima expresión con la ruptura del consenso entre los capitulares y el obispo Juan de Tarazona (1205-1211). Tras cinco años al frente de la diócesis, una parte del cabildo denunció ante la Santa Sede la ilegitimidad de la elección del obispo, al que culparon de abusos tales como simonía, inmoralidad y dilapidación de bienes de la iglesia pamplonesa. El papa Inocencio III delegó en el deán de Tarazona y en dos miembros de la catedral de Huesca, el obispo y uno de sus arcedianos, la decisión en torno al futuro del obispo, quien fue depuesto finalmente en $1211^{72}$.

La comparecencia de los capitulares ante el pontífice muestra la capacidad de los canónigos para agruparse en torno a un objetivo común. Lope de Tafalla, arcediano de la Cámara, Jimeno de Leoz, también arcediano, el chantre Pedro de Navaz, Guillermo de Leoz y los canónigos Pedro de Leoz, Sancho, Arnaldo del Pont, Pedro Andrecáin, I. López, Lope Martínez, S. Pérez y García fueron quienes efectuaron las denuncias contra su obispo, con el que, con toda evidencia, se habían distanciado después de haberlo elegido ${ }^{73}$. Tras el exilio del obispo, culparon al arcediano de la Tabla, Martín Pérez -que no había participado en las acusaciones al prelado depuesto- de haber recibido el arcedianato de manera irregular de Juan de Tarazona y de haber cometido simonía al entregar a su vez el arcedianato de Santa Gema a Pedro López de Tafalla ${ }^{74}$. El fracaso de esta tentativa permitió a Martín Pérez y a Pedro López de Tafalla conservar sus dignidades hasta, al menos, 1251 y 1223 respectivamente ${ }^{75}$, pero no impidió el ascenso de dos de los canónigos que habían actuado contra el de Tarazona. Así, Arnaldo del Pont ascendió de canónigo simple a prior en agosto de 1213, mientras que Pedro de Leoz, también canónigo, obtuvo en 1215 el arcedianato de la Cámara y la enfermería ${ }^{76}$. Esta acusación, unida a la promoción en el cabildo de algunos de los canónigos que habían protagonizado la acusación al obispo, evidencia el interés de este bloque de

\footnotetext{
72 Mansilla Reoyo, Demetrio, La documentación pontificia hasta Inocencio III, Roma, Instituto de Estudios Eclesiásticos, 1955, n. 415. Véase también Goñi, José, Historia de los obispos, I, p. 534.

${ }^{73}$ Mansilla Reoyo, Demetrio, La documentación pontificia, n. 415.

${ }^{74}$ Ibídem, n. 461. Véase también Goñi, José, Historia de los obispos, I, pp. 536-537.

${ }^{75}$ CDCP, n. 546 y n. 610. Mansilla Reoyo, Demetrio, La documentación pontificia, n. 461. Véase también Goñi, José, Historia de los obispos, I, 536-537.

${ }^{76}$ CDCP, n. 494, n. 500, n. 509, n. 523 y n. 608.
} 
capitulares por reforzar su posición en el cabildo y apartar al arcediano de la tabla de la dignidad más codiciada de la institución.

No es este el único caso en el que se documenta la expulsión de un obispo de la mitra episcopal; solo un par de décadas después del exilio de Juan de Tarazona se emprendió una acción contra el obispo de Huesca García de Gudal que culminó en la renuncia definitiva del prelado en julio de 1236. La falta de análisis centrados en esta suerte de conflictividades internas en las sedes peninsulares no permiten aportar más ejemplos; no obstante, la creciente autonomía de los cabildos de canónigos y el interés de las élites locales por controlar los principales puestos de la jerarquía eclesiástica permite aventurar que pugnas de este tipo fueron habituales, en paralelo al fortalecimiento y la creciente autonomía que los cabildos de canónigos experimentaron en este tiempo, aunque no siempre desembocasen en soluciones tan drásticas ${ }^{77}$. Sea como fuere, la destitución de Juan de Tarazona debe considerarse un reflejo de la fortaleza que alcanzó el cabildo a comienzos del siglo XIII, el cual fue capaz de sobreponerse a la autoridad episcopal y al poder jerárquico que ésta representa tras destituir a uno de sus obispos.

De esta manera, los conflictos y el entramado de afinidades, disensiones y enfrentamientos que se producen en estas décadas ponen de manifiesto la aparición de constantes luchas por el control de la institución catedralicia y por el acceso a los puestos de la alta jerarquía eclesiástica, donde se acentúa el protagonismo de los canónigos que buscaban cumplir sus ambiciones personales y, seguramente, consolidarse en dicha institución para participar en el despliegue de unas estrategias familiares de mayor alcance que conoceremos mejor a medida que sepamos algo más de las élites del reino navarro en este periodo. El siglo XIII se convierte, así, en un momento de intensa actividad política en la sede diocesana que terminó trastocando el sistema de dependencia de la jerarquía eclesiástica, hasta tal punto que un cabildo cada vez más autónomo y fuerte había sido capaz de desafiar dicho orden al forzar al exilio a la cabeza visible de la diócesis y provocar dos elecciones controvertidas con largos periodos de sede vacante.

\section{CONSIDERACIONES FINALES}

Las ideas expuestas a lo largo de este trabajo han permitido conocer mejor el comportamiento de los canónigos pamploneses en los dos primeros tercios del siglo XIII. El incremento del número de dignidades, su creciente prestigio y el atractivo de las rentas asociadas a las mismas favorecieron la incorporación de miembros de la nobleza y la burguesía local, convirtiendo al cabildo pamplonés en un espacio de promoción social y blanco de las estrategias familiares de estos grupos. Los conflictos internos que surgen en esta primera mitad del Doscientos, formulados tanto en las divisiones generadas entre los canónigos a la hora de escoger un nuevo

\footnotetext{
${ }^{77}$ Durán Gudiol, Antonio, Los obispos de Huesca durante los siglos XII y XIII, Zaragoza, Gobierno de Aragón, 1994, pp. 198-199.
} 
prelado, como en la oposición al ascenso de determinados capitulares a las principales dignidades y en la destitución del obispo Juan de Tarazona, apuntan a la formación de partidos y redes clientelares en la institución que parecen determinantes a la hora de favorecer o frenar la promoción interna de los religiosos. La sede navarra se presenta, así, como escenario de una creciente conflictividad donde se exteriorizan las tensiones entre las distintas instancias de poder, el episcopado y las familias que colocaron a sus familiares en el reino, en un contexto de cambio dinástico y de movilidad en el seno de la sociedad política del momento.

Ante estas evidencias, es necesario reivindicar la conveniencia de realizar nuevos trabajos que permitan definir las pautas de comportamiento de los canónigos a lo largo de la Edad Media, desentrañar la red de relaciones que los vincularon con las élites del reino y entender el cariz de los conflictos que determinaron la convivencia de capitulares y obispos. Para ello, es preciso ampliar el marco temporal expuesto aquí y aplicar los planteamientos desarrollados a contextos políticos diferentes, orientar los análisis al marco de relaciones entabladas entre el obispo, el cabildo y los concejos urbanos para considerar el modo en que la presencia de miembros de la burguesía local pudo influir en dichas relaciones e incluso comenzar una revisión de las interacciones entre monarquía, episcopado y cabildo. En última instancia, consideramos que la historiografía navarra debe apostar por una renovación de los estudios eclesiásticos que entienda la catedral como una pieza fundamental en el entramado de los espacios de poder que coexistieron en el reino y reconozca a sus integrantes como parte de una élite susceptible de ser analizada en los estudios sobre la monarquía y el Estado, la sociedad política o las oligarquías urbanas.

\section{BiBLIOGRAFÍA}

Abella Samitier, Juan, «La comarca de la Valdonsella en las relaciones entre Aragón y Navarra a fines de la Edad Media», Príncipe de Viana, 2011, vol. 72, n 253, pp. 335-348.

Barralis, Christine; Boudet, Jean-Patrice; Delivrè, Fabrice; Genet, Jean-Philippe (dirs.), Église et État, Église ou État?, Paris-Roma, Publications de la Sorbonne-École Française de Rome, 2014.

Beech, George, «Prosopography», en Powell, James M. (ed.), Medieval Studies: an Introduction, Syracuse, Universidad de Siracusa, 1979, pp. 151-184.

Bulst, Neithard; Genet, Jean-Philippe (eds.), Medieval Lives and the Historian. Studies on Medieval Prosopography, Kalamazoo, Medieval Institute Publications-Western Michigan University, 1986. 
Carrasco Pérez, Juan, «Sociedades mercantiles en los espacios urbanos del camino de Santiago (1252-1425): de San Juan de Pie de Puerto a Burgos», en Las sociedades urbanas en la España medieval, XXIX Semana de Estudios Medievales de Estella, Pamplona, Gobierno de Navarra, 2003, pp. 243-276.

Castro, José Ramón; Idoate, Florencio, Catálogo del Archivo General de Navarra. Catálogo de la sección de Comptos. Documentos. Tomo I (842-1331), Pamplona, Aramburu, 1952.

Ciérbide Martinena, Ricardo; Ramos Remedios, Emiliana, Documentación medieval del Archivo Municipal de Pamplona (1129-1356), San Sebastián, Sociedad de Estudios Vascos, 1998.

Ciérbide Martinena, Ricardo, «El nombre de los navarros», en Ramírez Sádaba, José Luis (coord.), La onomástica en Navarra y su relación con la de España. Actas de las primeras jornadas de Onomástica (Pamplona, 2003), Pamplona, Universidad Pública de Navarra, 2005, pp. 15-34.

Conesa Soriano, Julia, «The Cathedral Chapter of Barcelona and the urban elites at the end of the fifteenth century», en Sabaté i Curull, Flocel (dir.), Life and Religion in Middle Ages, Newcastle Upon Tyne, Cambridge Scholars Publishing, 2015, pp. 234-246.

Díaz Ibáñez, Jorge, «El cabildo catedralicio conquense en el siglo XIII», Anuario de estudios medievales, 1997, vol. 27, $\mathrm{n}^{\circ}$ 1, pp. 315-346.

Díaz Ibáñez, Jorge, «La incorporación de la nobleza al alto clero en el reino de Castilla durante la Baja Edad Media», Anuario de estudios medievales, 2005, vol. 35, n 2, pp. 557-604.

Domínguez Sánchez, Santiago, Documentos de Clemente IV (1265-1268) referentes a España, León, Universidad de León, 1996.

Domínguez Sánchez, Santiago, Documentos de Nicolás IV (1288-1292) referentes a España, León, Universidad de León, 2009.

Durán Gudiol, Antonio, El castillo abadía de Montearagón (siglos XII y XIII), Zaragoza, Institución Fernando el Católico, 1987.

Durán Gudiol, Antonio, Los obispos de Huesca durante los siglos XII y XIII, Zaragoza, Gobierno de Aragón, 1994, pp. 198-199. 
Fortún Pérez de Ciriza, Luis Javier, «Organización eclesiástica», en Martín Duque, Ángel J. (dir.), Gran Atlas de Navarra, II, Pamplona, Caja de Ahorros de Navarra, 1986, pp. 138-143.

García Arancón, María Raquel, «La Junta de Infanzones de Obanos hasta 1281», Príncipe de Viana, 1984, vol. 45, nº 173, pp. 527-560.

García Arancón, María Raquel, «El clero secular en Navarra a mediados del siglo XIII», Hispania Sacra, 1999, vol. 51, nº 104, pp. 676-677.

García Arancón, María Raquel, «Tres linajes navarros bajo la casa de Champaña», Aragón en la Edad Media, 1999, n 14-15/1, pp. 669-686.

García Arancón, María Raquel, Archivo General de Navarra. Sección de Comptos. Registro $n^{\circ} 1$ (1259 y 1266), San Sebastián, Sociedad de Estudios Vascos, 2000, pp. 121-128.

García de la Borbolla, Ángeles, «La identidad de los canónigos de la catedral de Pamplona en el siglo XIV: figuras destacadas y dignidades», Príncipe de Viana, 2016, vol. 77, nº 265, pp. 715-731.

García de la Borbolla, Ángeles, «El cabildo de la catedral de Pamplona y la Navarrería en la segunda mitad del siglo XIV: la creación de un condominio», Edad Media: revista de historia, 2016, nº 17, pp. 255-273.

García de la Borbolla, Ángeles, «Encuentros y desencuentros en el seno del cabildo de la catedral de Pamplona (siglo XIV)», Historia. Instituciones. Documentos, 2016, nº 43, pp. 171-182.

García Larragueta, Santos Agustín, El gran priorado de Navarra de la Orden de San Juan de Jerusalén. Siglos XII-XIII, Pamplona, Diputación Foral de Navarra, 1957.

García Larragueta, Santos Agustín, «El becerro de Roncesvalles», Príncipe de Viana, 1983, vol. 44, n 168-170, pp. 111-172.

Genet, Jean-Philippe, «Medieval Prosopographical Research at the University of Paris I», Medieval Prosopography, 1980, nº 1, pp. 1-13.

Goñi Gaztambide, José, Catálogo del Archivo Catedral de Pamplona (829-1500), Pamplona, Diputación Foral de Navarra, 1965. 
Goñi Gaztambide, José, «La formación intelectual de los navarros en la Edad Media (siglos XII-XV)», Estudios de la Edad Media de la Corona de Aragón, 1975, vol. 10, pp. 143-303.

Goñi Gaztambide, José, Historia de los obispos de Pamplona. Tomo I. Siglos IVXIII, Pamplona, Gobierno de Navarra, 1979.

Goñi Gaztambide, José, «Episcopado y cabildo», en Jusué Simonena, Carmen (dir.), La catedral de Pamplona. Tomo I, Pamplona, Caja de Ahorros de Navarra-Gobierno de Navarra, 1994, pp. 33-69.

Goñi Gaztambide, José, Colección diplomática de la catedral de Pamplona. 8291243, Pamplona, Gobierno de Navarra, 1997.

Goñi Gaztambide, José, Los priores de la catedral de Pamplona, Pamplona, Mintzoa, 2000.

Guijarro González, Susana, «Jerarquía y redes sociales en la Castilla medieval: la provisión de beneficios eclesiásticos en el cabildo de la catedral de Burgos (1390-1440)», 2008, Anuario de estudios medievales, nº 38/1, pp. 271-299.

Hidalgo Sánchez, Santiaga, «Obispo y cabildo, promotores en la Edad Media: el caso del claustro de Pamplona», Cuadernos de la Cátedra de Patrimonio y Arte Navarro, 2007, n 2, pp. 279-292.

Ilundáin Chamarro, Javier, «Prosopografía de la baja nobleza navarra bajo la dinastía de Champaña (1234-1274)», en Navarra: memoria e imagen. Actas del VI Congreso de Historia de Navarra. Pamplona, 2006, vol. I, Pamplona, Eunate, 2006, pp. 173-190.

Irurita Lusarreta, María Ángeles, El municipio de Pamplona en la Edad Media, Pamplona, Ayuntamiento de Pamplona, 1959.

Jiménez Gutiérrez, Francisco Javier, «El cabildo pamplonés en el siglo XIV. Un análisis prosopográfico», Príncipe de Viana, 1992, vol. 53, n 196, pp. 391408.

Laliena Corbera, Carlos, «La administración de un patrimonio eclesiástico. El libro contable del obispo de Huesca Guillem Ponç de Fenollet (1463)», Aragón en la Edad Media, 1987, nº 7, pp. 151-176. 
Lop Otín, María José, «Las catedrales y los cabildos catedralicios en la Corona de Castilla durante la Edad Media. Un balance historiográfico», En la España medieval, 2003, $\mathrm{n}^{\circ}$ 26, pp. 371-404.

Mansilla Reoyo, Demetrio, La documentación pontificia hasta Inocencio III (9651216), Roma, Instituto de Estudios Eclesiásticos, 1955.

Martín Duque, Ángel Juan, «Sancho VI el Sabio y el fuero de Vitoria», Príncipe de Viana, 2002, vol. 63, n 227, pp. 773-790.

Millet, Hélène (ed.), Informatique et prosopographie, Paris, Centre National de la Recherche Scientifique, 1985.

Miranda García, Fermín, Roncesvalles. Trayectoria patrimonial (siglos XII-XIX), Pamplona, Gobierno de Navarra, 1993.

Miranda García, Fermín, «Eclesiásticos al servicio de la monarquía navarra (11341274). Un punto de partida», en Vasconcelos Vilar, Herminia; João Branco, María (dirs.), Eclesiastics and political state building in the iberian monarchies, $13^{\text {th }}-15^{\text {th }}$ centuries, Evora, Publicacões do Cidehus, 2016, pp. 26-42.

Moxo y Montoliu, Francisco, La casa de Luna (1276-1348). Factor político y lazos de sangre en la ascensión de un linaje aragonés, Madrid, Gráficas Arias Montano, 1990.

Munita Loinaz, José Antonio, «Regesta documental del monasterio de la Oliva (1132-1526)», Príncipe de Viana, 1995, vol. 56, nº 205, pp. 343-484.

Munsuri Rosado, Nieves, «Clero e Iglesia en la Baja Edad Media hispánica: estado de la cuestión», e-Humanista: Journal of Iberian Studies, 2008, $\mathrm{n}^{\circ}$ 10, pp. 133-169.

Narbona Vizcaíno, Rafael, «El método prosopográfico y el estudio de las élites de poder bajomedievales», en El Estado en la Baja Edad Media: nuevas perspectivas metodológicas, Zaragoza, Universidad de Zaragoza, 1999, pp. 31-49.

Nieto Soria, José Manuel, Iglesia y poder real en Castilla. El episcopado, 12501350, Madrid, Universidad Complutense, 1988. 
Nieto Soria, José Manuel; Díaz Ibáñez, Jorge, «Élites y clientelas eclesiásticas (siglos XIII al XV): propuestas metodológicas desde el caso castellano», en Barata, Filipe Thermudo (coord.), Elites e redes clientelares na Idade Média, Lisboa, Colibrí, 2001, pp. 109-139.

Ostolaza Elizondo, María Isabel., Colección diplomática de Santa María de Roncesvalles (1127-1300), Pamplona, Diputación Foral de Navarra, 1978.

Pérez Rodríguez, Francisco Javier; González Vázquez, Marta, «Aproximación al estudio de las relaciones familiares y de poder en una institución eclesiástica: el cabildo compostelano de los siglos XII y XIII», Hispania, 1993, vol. 59, $\mathrm{n}^{\mathrm{o}}$ 185, pp. 1091-1098.

Pons Alós, Vicente, «Los canónigos de la catedral de Valencia (1375-1520). Aproximación a su prosopografía», Anuario de estudios medievales, 2005, vol. 35, n 2, pp. 907-950.

Ramírez Vaquero, Eloísa, «La nobleza bajomedieval navarra. Pautas de comportamiento y actitudes políticas», en La nobleza peninsular en la Edad Media. VI Congreso de Estudios Medievales, Ávila, Fundación Sánchez Albornoz, 1997, pp. 297-324.

Ramírez Vaquero, Eloísa, «The first urban oligarchic networks in Navarre: Pamplona, 1100-1328», en Asenjo-González, María (dir.), Oligarchy and patronage in late medieval Spanish urban society, Turnhout, Brepols, 2009, pp. 117-152.

Ramírez Vaquero, Eloísa, «The elites of Pamplona at the end of the Middle Ages: the road to ennoblement», en Asenjo González, María (ed.), Urban elites and aristocratic behaviour in the Spanish kingdoms at the end of the Middle Ages, Turnhout, Brepols, 2013, pp. 61-85.

Rodriguez Llopis, Miguel; García Díaz, Isabel, Iglesia y sociedad feudal: el cabildo de la catedral de Murcia en la Baja Edad Media, Murcia, Universidad de Murcia, 1994.

Vasconcelos Vilar, Herminia, «Les clerici regis et le service du roi dans le Portugal des XIII ${ }^{\mathrm{e}}$ et XIV ${ }^{\mathrm{e}}$ siècles», en Barralis, C.; Boudet, J-P.; Delivrè, F.; Genet, J-P. (dirs.), Église et État, Église ou État?, pp. 153-156.

Vigil Montes, Néstor, «Últimas aportaciones a la historia de los cabildos catedralicios en Castilla y Portugal durante la Edad Media (2000-2010)», Studium Ovetense, 2010, nº 28, pp. 103-133. 